\title{
BULLYING E O DESAFIO NO CONTEXTO EDUCACIONAL
}

\section{ARTIGO DE REVISÃO}

SOARES, Jose Roberto Vera ${ }^{1}$

OLIVEIRA, Ginarajadaça Ferreira dos Santos²

SOARES, Jose Roberto Vera. OLIVEIRA, Ginarajadaça Ferreira dos Santos. Bullying e o desafio no contexto educacional. Revista Científica Multidisciplinar Núcleo do Conhecimento. Ano 04, Ed. 09, Vol. 05, pp. 68-78. Setembro de 2019. ISSN: 24480959

\section{RESUMO}

A palavra bullying tem sua origem da palavra inglesa bully, que significa dizer ameaçar, oprimir, intimidar e maltratar. É um fenômeno mais antigo no ambiente escolar e não tem sua origem por fatores socioeconômicos uma vez que se instala entre as mais diversas camadas da sociedade. O bullying faz parte do centro de muitos assuntos discutidos nos dias atuais e em todos os seguimentos educacionais. Sua complexidade é grande e tem causado atitudes bárbaras, que agridem friamente a vítima e indiretamente a sociedade, pois abrangem todos os atos de violência sejam elas físicas ou psicológicas que ocorre de forma intencional e repetidamente contra um ou mais alunos, que se consideram frágeis e incapazes de se defenderem. Este

\footnotetext{
${ }^{1}$ Graduação em Ciências Naturais pela Universidade Federal do Amazonas - UFAM (2004), Graduação em Engenharia Florestal -UTAM (2004); Pós-Graduação em Educação Ambiental pela Faculdade de Ciências Administrativas e de Tecnologia de Rondônia (2018); Mestrando em Ciências da Educação pela St Alcuin Of York Anglican College - AEBRA (2019).

2 Graduação em Ciências Biológicas pela Fundação de Ensino Superior de Olinda (1985), Especialização em Micologia-UFPE; Mestrado em Biologia de Fungos pela UFPE (2003) e Doutorado em Biotecnologia pela UFAM (2011).
} 
artigo teve como objetivo conhecer e compreender o fenômeno chamado bullying e como ele se configura no ambiente escolar. A pesquisa foi realizada por meio de uma pesquisa bibliográfica utilizando como fundamentação teórica artigos científicos, teses e leis pertinentes ao assunto. Concluiu-se que as informações obtidas pelo estudo são primordiais na busca de reduzir o bullying escola, sendo uma das alternativas para esta redução o fortalecimento das relações entre escola e alunos além de um maior preparo dos professores e demais funcionários. A temática é de extrema relevância no ambiente escolar, onde é possível observar a urgência de práticas educativas e que enfrentem essa problemática, potencializando a prevenção como mais um meio de promover o bem-estar social.

Palavras-chaves: Educação, escola, violência.

\section{INTRODUÇÃO}

O Bullying no ambiente escolar não é um fenômeno relativamente novo. Mas que vem assumindo grandes proporções e a escola não sabe como mitigar este problema. Atualmente este tema é uma das preocupações da sociedade sendo necessário esclarecer os verdadeiros fatores que favorecem a violência no ambiente escolar (QUEIROZ, 2017).

Há um grande número de casos de violência escolar relatados nos últimos tempos entre os jovens da faixa etária de 10 a 21 anos, tem se mostrado estatisticamente entre os que mais matam e morrem no mundo todo. Podemos frisar que essa faixa etária da qual se encontram é onde se encontram na sua vida escolar, ou seja, grande parte das práticas de bullying acontecem no ambiente escolar.

Este termo é utilizado para definir atos de violência e atentados físicos e morais, de modo intencional e repetidos praticados por um indivíduo ou um grupo, com o objetivo de causar dor e sofrimento em uma relação de desigualdade de poder. As instituições e os educadores de ensino acabam se deparando com situações que estes comportamentos violentos acontecem continuamente. 
A violência escolar é uma pauta que requer um olhar cuidadoso e atento dos profissionais da educação, entretanto quando é tratado é percebido apenas situações nas quais os alunos trocam agressões físicas e quebram pertences. Onde na realidade a violência é bem maior e se manifesta nos relacionamentos educativos, no processo de ensino-aprendizagem ou até mesmo no âmbito educacional. A escola é uma instituição social é um lugar onde todas as diferenças acabam se achando e também é um local permanente de conflitos, fato este que se dá pelas inúmeras diferenças na forma de educação, valores familiares, culturais, religiosos e étnicos, onde o ambiente escolar acaba promovendo o correto direcionamento (SÓ, 2010).

Compreender as diferenças e aprender a lidar com elas, trabalhando posturas e ações construtivas para solucionar esses conflitos devem fazer parte do aprendizado de modo a minimizar o crescimento da violência no ambiente escolar.

Diante do exposto este estudo teve a finalidade de conhecer e compreender o fenômeno bullying e com o ele é configura no ambiente escolar, norteando a pesquisa bibliográfica por autores com publicações realizadas em periódicos de caráter científico e plataformas oficiais para consulta da existência de leis que abrangem a temática. Aprofundando os conceitos e conhecendo como a escola lida com a gestão desta problemática.

\section{CONTEXTUALIZANDO A ORIGEM DO BULLYING}

Atualmente o bullying é um problema mundial e atinge diretamente principalmente crianças e adolescentes sofrem com algum tipo de violência sejam elas físicas, morais e na forma mascarada de brincadeiras, sendo estes comportamentos definidos como bullying. Tal termo é usado para definir atos de violência física e moral de forma intencional e repetida que é praticada por um ou mais indivíduos com o intuito de causar dor, sofrimento e angústia do outro.

O bullying é um fenômeno que começou a ser pesquisado na Europa entre os jovens de 10 a 20 anos de idade, pois a taxa de suicídios entre esta faixa etária era elevada. Constatou-se que os pais ou responsáveis juntamente com a escola não davam a 
devida atenção a esses jovens, pois geralmente achavam as ofensas como brincadeiras bobas e acabavam tomando medidas sem preparo algum. De acordo com especialista o bullying pode ocorrer em qualquer faixa social e de escolaridade, um simples apelido inofensivo pode afetar o lado emocional e físico do alvo das ofensas (GRILLO; SANTOS, 2015).

É importante apontar que o bullying são atitudes de cunho intencional e premeditados, sistematizados e planejados, realizado de forma repetitiva nos mais diferentes tipos de agressões, sobretudo no meio escolar ou fora dele. Essas atitudes geralmente não apontam causas especificas ou justificáveis, que de forma quase espontânea os denominados mais fortes utilizam os mais fracos como simples objeto de diversão e humilhação as suas vítimas (MELO, 2010).

A violência escolar ou intimidação sistemática é dado pelo desequilíbrio de forças. $E$ as principais classificações são o bullying direto que inclui ações agressivas de formas físicas e verbais e uma outra forma a indireta, que é caracterizada pela exclusão social, levando a vitimização relacionada a agressividade das quais tenham sido salvos. Aponta-se que durante a adolescência a vítima possui poucos recursos para esquivar-se ou defender-se das agressões (FRANCISCO; COIMBRA, 2015).

Segundo Mota et.al (2018) este fenômeno acaba se manifestando de várias formas e modos distintos sendo algumas delas a verbalmente, por meio de insultos, apelidos pejorativos, xingamentos e comentários diminutivos; física como por exemplo bater ou cuspir e também o cyberbullying que é promovido através dos espaços virtuais. Também pode-se incluir as práticas com fofocas e exclusão social.

Em muitos casos as pessoas que praticam o bullying são em sua grande maioria pessoas / indivíduos que não possuem uma boa educação e estrutura familiar desestabilizada e com problemas tornando este individuo difícil em não aceitar as diferenças. Os agressores acabam apresentando desde pequenos uma grande resistência as normas impostas em determinados ambientes, não toleram ser contrariados ou frustrados, e acabam tendo vínculos com a prática de pequenos delitos (QUEIROZ, 2017). 
Para os autores Neto (2011) e Queiroz (2017) o bullying é como um ato popular que tendência a se envolver e mistura-se com vários outros comportamentos antissociais existentes ou criados, e que acabam visualizando a sua agressividade como uma boa qualidade. Muitos são esses comportamentos assim como também são vários personagens que cooperam para estes atos de violência, cabe-se identificá-los da melhor maneira e compreender as nuances das suas complexidades e implicações:

- Agressor: é apontado como aquele que origina o ataque ao outro indivíduo que se torna incapaz de defender-se, geralmente e tido como a mais forte e não aceita ser contrariado.

- Alvo/autor ou vítima agressora: são os que são mutuamente tanto o agressor quanto vítima, e o indivíduo que transfere as agressões sofridas para um outro aparentemente mais frágil a ele.

- Vítima: geralmente é pouco sociável, sofre as agressões repetidamente dos outros indivíduos ou de um determinado grupo deles, aparentemente apresenta caraterísticas de um ser frágil diante de seus colegas, tem alta sensibilidade, timidez e pouca autoestima.

- Observador ou espectador: e o indivíduo que não se envolve de nenhuma forma aos atos de agressões realizados aos demais, assistem e convivem e adotando uma postura indiferente, o que caracteriza uma lei adota pela grande maioria dos alunos, que é a lei do silêncio, onde os mesmos acabam tendo receio de virar um novo alvo para o agressor.

Sejam qual for a atuação de cada indivíduo e independente das caracterizações dos envolvidos, percebe-se que quando não há uma intervenção de forma efetiva contra essas agressões de bullying, a escola acaba se tornando um ambiente contaminado. Onde todos os alunos são afetados diretamente e negativamente sem haver exceções, experimentando sentimentos de ansiedade e medo. Além de identificar como os alunos se tornam vítimas, agressores ou espectadores tornando-se 
importante para que a escola e a família também possam criar maneiras e obter ações efetivas contra o bullying (SÓ, 2010).

\subsection{O PAPEL DA ESCOLA E FAMÍLIA NO DESAFIO AO COMBATE DO BULLYING}

A escola é tradicionalmente entendida como um lugar de aprendizado, avaliando-se o desenvolvimento do aprendizado dos alunos baseado em notas de avaliações e no cumprimento de suas obrigações acadêmicas.

Entre as atividades exercidas pelos alunos está o fato de ser incentivado a competir e estar sempre comparando os padrões pré-determinadas juntamente como o modelo que e apresentado na escola, que na grande parte são modelos de cunho competitivos e capitalistas. Alguns modelos pedagógicos apresentam de forma mascarada aspectos culturais que de certa forma podem promover a prática do bullying (OLIVEIRA, 2015).

A escola se ampara em três documentos legais de abrangências nacional e internacional como uma solução ao problema do bullying e podemos citar a Constituição Federal do Brasil, o estatuto da Criança e do Adolescente e a Convenção sobre os Direitos da Criança da Organização das Nações Unidas que baseiam o entendimento relacionado ao desenvolvimento e educação das crianças e adolescentes. É unanime que todos esses documentos preveem direitos ao respeito e dignidade, sendo a educação entendida como um provedor do desenvolvimento e do seu exercício da cidadania (ZEQUINÃO et al, 2016).

Para Só (2010) alguns princípios acabam direcionando o caráter do ser humano desde de sua infância. Sendo a escola e a família os essenciais pilares na construção desses valores e por consequência a formação da personalidade do educando. Para Cury (2003) uma ferramenta educacional que ainda é insubstituível ainda é o diálogo, onde a deve haver a presença da autoridade nas relações de pai-filho e professor-aluno, podendo ter a verdadeira autoridade por meio da inteligência e amor. 
Uma outra atitude apontada é a dos pais, que devem ser exemplos de boas atitudes e participar da vida social e escolar dos filhos, pois onde há uma família equilibrada há também filhos equilibrados (CHALITA, 2008).

Os atos de agressões ou assédio escolar caracterizam ações ilícitas, pois não estão autorizados pelo ordenamento jurídico e desrespeitem os princípios constitucionais e - Código Civil, que aponta e determina ao todo ato ilícito que tenha como consequências os danos alheios cabem a este o dever de indenizar. É cabível a escola, que possui práticas de assédios escolar a responsabilidade de se enquadrar ao código de defesa do consumidor, uma vez que a escola é uma instituição prestadora de serviços ao consumidor e também são responsáveis pelos atos de assédio escolar.

Segundo Só (2010) todos devem estar compromissados de que o bullying não será mais um fato tolerado, e as estratégias para essa mitigação devem ser definidas em cada escola, observando-se as características da comunidade da qual está inserida. O incentivo aos alunos, abrindo espaço para a participação em decisões e no desenvolvimento de projetos é uma garantia em obter sucesso.

O profissional educador tem a capacidade de interagir na prevenção e resolução desses problemas ocorridos no meio educacional. O comportamento dos alunos sob um olhar mais atento deve ser o primeiro passo, dentro e fora da sala de aula e identificar se existe deficiência particulares no rendimento escolar. Através do incentivo a solidariedade, a generosidade e o respeito as várias diferenças, por meio de conversas, trabalhos sócio didáticos e palestras de conscientização que incentivem a paz e a tolerância ao diferente (SÓ, 2010; ZEQUINÃO et al, 2016).

Uma das estratégias que tem dado maior eficácia e bons resultados são as ações que visam a conscientização dos profissionais que fazem parte do corpo escolar e dos pais e responsáveis em relação do problema (CHALITA, 2008). Faz parte do pensar o rejeito a qualquer tipo de discriminação, levando a pratica preconceituosa de qual for o tipo a negar de maneira radical a democracia (FREIRE, 1997). 
Dada a complexidade deste problema e as implicações que vem dessa forma de violência, relacionados ao espaço educativo e principalmente aos alunos que nele estão inseridos. A união da escola com a família tem um papel importante na missão de promover aos educandos um ambiente harmonioso, atuando de forma direta na formação de indivíduos autênticos e participativa e de alta-estima elevada, visto que desta forma estarão formando pessoas que se amam, que se zelam, se aceitem, se respeitem e se fazem respeitar, são seguras de suas decisões e possuem o reconhecimento dos seus valores e virtudes, e assume as suas limitações.

\section{CONCLUSÃO}

O bullying sem sombra de dúvidas é uma ação que possui teor extremamente prejudicial ao bem-estar de todos nós, diferentemente das demais formas de agressões, o bullying acaba trazendo consigo muitas consequências danosas que afetam a saúde física, mental e social de todos os envolvido, sejam elas as vitimizadas, as agressoras ou as espectadoras.

Salienta-se que um dos grandes problemas que promovem as agressões de bullying é a falta de conhecimento e informação dos pais, dos seus responsáveis e dos professores, visto que eles possuem maior interação com o indivíduo a ser educado. Pois eles acreditam ainda que essas atitudes realizadas entre esses jovens são apenas brincadeiras sem maldade e é característico da idade ou da fase que os mesmos estão passando.

O estudo realizado favoreceu um maior entendimento acerca do fenômeno, entender algumas das suas diversas formas, variações dentro do contexto escolar e as suas possíveis consequentes.

A pesquisa evidenciou a ocorrência de bullying entre os alunos na escola, mostrando que o contexto escolar tem se constituído em um espaço para a promoção deste tipo de violência. Onde suas vítimas se sentem desprotegidas e sempre vulneráveis quanto ao seu agressor. 
O medo é o grande vilão na vida dessas pessoas, vítimas, causando sofrimento, fragilidades, incapacidade e baixa autoestima e com consequências psicológicas de curto e a longo prazo. Esses fatores juntamente com as situações de constrangimento e humilhação da qual a vítima é exposta, muitas vezes acabam repelindo o sentimento em procurar ajuda e revele a alguém que demostre confiança o que está acontecendo.

Podemos citar que para Bittencourt (2012) afirma que é importante criar uma cultura de ações contra o bullying, mostrando ao agressor que esses atos não são saudáveis e nem permitidos em nenhuma hipótese na sociedade em que se vive. Mas para ter essa autonomia e cultivar essas boas ações é preciso que seja realizada uma investigação para realizar a identificação desta prática de violência escolar.

A maior parte dos agressores não assumem seus atos, pois em seus consentimentos são apenas brincadeiras divertidas, pois muitas dessas brincadeiras não têm teor saudável para ambos os lados, um dos lados acaba se divertindo com a custa do sofrimento do outro. Percebemos que as agressões são mais frequentes e em maior número entre o sexo masculino. Tais discussões são comuns nas relações humanas e acontecem o tempo todo no ambiente escolar, e principalmente dentro da sala de aula, da qual o professore deverá estar sempre atento à frequência que essas situações acontecem e quais são seus envolvidos. Desta forma poderá perceber o problema e poderá tomar atitudes que faça a intervenção necessária.

Averiguamos também que os profissionais da educação ainda não se sentem confortáveis em tomar decisões de iniciativas para a prevenção e intervenção a este fato, acabam por alegarem que conhecem o fenômeno bullying mas que não consideram capacitados de intervir, pois acabam esbarrando em falta de apoio da escola e também da familiar, principalmente.

É um grande desafio mitigar todos os elementos que proporcionem a prática do bullying escolar, mas ainda há um grande desejo de se viver em uma sociedade mais justa, generosa e em harmonia, nos fazendo crer que é possível uma união entre a família e escola no sentindo que possibilite o respeito, a tolerância e a aceitação da diferença do outro e de si próprio. 
Diante do exposto podemos dizer que a inexistência de políticas públicas que determinem a necessidade de priorização das ações de prevenção relacionadas a assédio escolar ou bullying, o que nos levam a apontar que esses alunos estão expostos aos riscos dos abusos de seus pares. Além disso, os agressores acabam não recebendo o apoio devido para retirá-lo dos caminhos que causarão um certo dano por toda a sua vida.

A escola é um leque de possibilidades para a exploração e identificação das possíveis estratégias que fariam parte da prevenção e intervenção do bullying, considerando a realidade que vivem e convivem as personagens deste cenário, destacando também a formação continuada dos professores, projetos educativos, palestras educacionais e de conscientização para todos que fazem parte do corpo escolar e que incluem a família. Pois não podemos permitir que o bullying seja tratado como algo irrelevante e banal em nossa sociedade e convivendo a tolerância entre a escola e a relação que esta violência propicia.

As distintas instituições escola e família precisam deixam de apontar a responsabilidade de uma para outra. Onde os pais acusam a escola de não possuírem autoridade em disciplinar os alunos e a escola acusa os pais te não determinarem limites aos seus filhos. Pois cabe a escola buscar ajuda e apoio necessário aos pais e responsáveis no diz respeito aos limites, ética, respeito aos mais velhos e aos mais frágeis. Já a família deve assumir o papel de formadora de cidadão ao não tolerar e acolher todas as atitudes dos seus filhos.

Espera-se com este estudo a contribuição para a reflexão e conscientização sobre este tema, sendo útil para futuros debates e ser fonte de possíveis estudos.

\section{REFERÊNCIAS}

BITTENCOURT, Daniana Moreira Barros, (2012). "FENÔMENO BULLYING NA ESCOLA". Práxis Educacional, vol. 8, núm. 13, pag. 211-231. 
CHALITA, Gabriel. Pedagogia da amizade - bullying: o sofrimento das vítimas e dos agressores. São Paulo: Editora Gente. 2008.

CURY, Augusto J. Pais brilhantes, professores fascinantes. Rio de Janeiro: Sextante. 2003.

FRANCISCO, Marcos Vinicius; COIMBRA, Renata Maria. Análise do bullying escolar sob o enfoque da psicologia histórico-cultural. Estud. psicol. (Natal), Natal, v. 20, n. 3, p. 184-195, Sept. 2015 . Available from $<$ http://www.scielo.br/scielo.php?script=sci_ arttext\&pid $\quad=$ S1413294X2015000300184\&lng=en\&nrm=iso $>$. access on 18 Aug. 2019. http://dx.doi. org/10.5935/1678-4669.20150020.

FREIRE, Paulo. Pedagogia da autonomia: saberes necessários à pratica educativa. São Paulo: Editora Paz e Terra, 1997.

GRILLO, M.A; SANTOS, A.S. Bullying na escola. Bullying in school. Colloquium Humanarum. 12, 3, 61-74, July 2015.

MELO, Josevaldo Araújo de. Bullying na escola: como identificá-lo, como preveni-lo, como combatê-lo. 3 ed. Recife: EDUPE, 2010.

MOTA, Rosana Santos et al. ADOLESCENTES ESCOLARES: ASSOCIAÇÃO ENTRE VIVÊNCIA DE BULLYING E CONSUMO DE ÁLCOOL/DROGAS. Texto contexto enferm., Florianópolis , v. 27, n. 3, e3650017, 2018 . Available from $<\mathrm{http}: / / w w w . s c i e l o$ .br/scielo.php?script=sci_arttext\&pid=S010407072018000300332\&Ing=en\&nrm=iso >. Access on 16 Aug. 2019. Epub Sep 13, 2018. http://dx.doi.org/10.1590/0104-070720180036 50017.

NETO, Aramis Antônio Lopes. BULLYING: saber identificar e como prevenir. São Paulo: Brasiliense, 2011.

OLIVEIRA, Edjôfre Coelho. O bullying na escola: como alunos e professores lidam com esta violência? Revista Fundamentos, V.2, n.1, 2015. Disponível em: 
<http://www.ojs.ufpi.br/ index.php/fundamentos/article/view/3727>. Acesso em: 18 ago. 2019.

QUEIROZ, Mayara R. Maia Penafort. Bullying: A Intervenção da Escola Estadual Tiradentes aDiante desse Contexto. Revista Científica Multidisciplinar Núcleo do Conhecimento. Edição 05. Ano 02, Vol. 01. pp 956-973, Julho de 2017. ISSN:24480959.

SÓ, Sheila Lucas. Bullying nas escolas: uma proposta de intervenção. 2010. 33 f. Monografia (Especialização) - Curso de Especialização em Psicologia Escolar, Universidade Federal do Rio Grande do Sul, Santa Catarina, 2010.

ZEQUINAO, Marcela Almeida et al . Bullying escolar: um fenômeno multifacetado. Educ. Pesqui., São Paulo , v. 42, n. 1, p. 181-198, Mar. 2016 . Disponível em: <http://www.scielo. br/scielo.php?script=sci_arttext\&pid=S151797022016000100181\&lng=en\&nrm=iso $>$. Acesso em: 17 Aug. 2019. http://dx.doi.org/10.1590/S1517-9702201603138354.

Enviado: Agosto, 2019.

Aprovado: Setembro, 2019. 